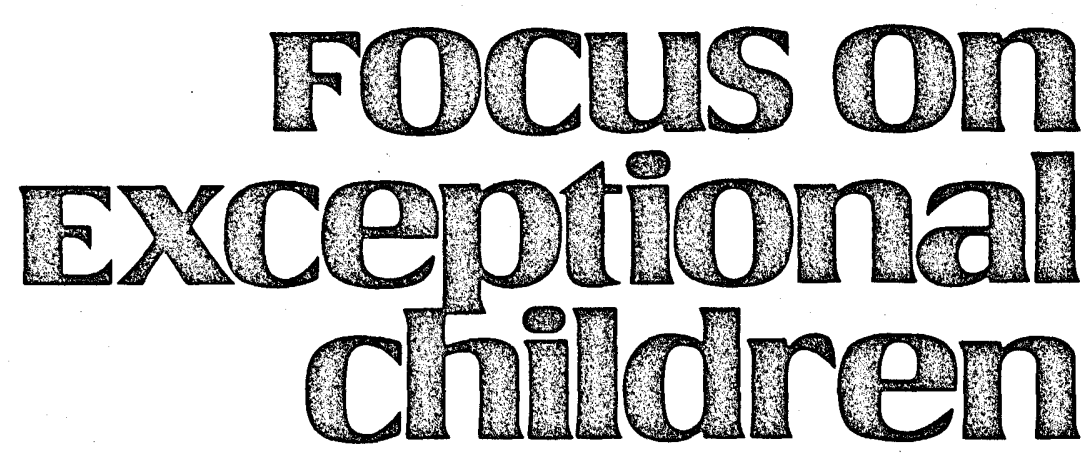

\title{
Public Law 99-457, Part H, Infant and Toddler Programs: Status and Implications
}

\author{
Ron P. Colarusso and Thomas G. Kana
}

The United States Congress enacted Public Law 99-457, the Education of the Handicapped Act Amendments of 1986, with the intent of providing comprehensive services to preschool handicapped children and their families. The law's contents and requirements hold great opportunity as well as great challenge for a variety of professionals. In establishing a national policy for early intervention, this law provides incentives and assistance to states for the extension of existing special education services from school age to birth. In this extension of educational services, PL 99-457 breaks new ground in its recognition of the family's critical impact upon development. It also requires the application of a variety of models, other than traditional education models, employing a team of multidisciplinary professionals to serve very young disabled children and their families.

Public Law 99-457 divides the preschool population into two groups: infants/toddlers (birth to 3 years) and preschoolers ( 3 to 6 years). Title I (Part H), Handicapped Infants and Toddlers, addresses the needs of very young handicapped children and focuses on the child's developmental and medical needs as well as the importance of the family. Title II (Part B), Handicapped Children Three Through Five, amends the provisions for the preschool handicapped under PL 94-142, The Education of the Handicapped Act of 1975. Following a brief description of Part $B_{\text {; }}$ the remainder of this article addresses the implications and issues unique to Part $\mathrm{H}$.

\section{PROVISIONS OF PART B}

Although the focus of this article is the presentation of Part $\mathrm{H}$ programs, a brief discussion of Part B is warranted because of the interrelation of the two parts. Part B adds a mandate to the previously permissive section of PL 94-142 addressing the preschool handicapped. It requires that each state provide a free, appropriate public education along with related services to all eligible children with handicaps ages 3 through 5 .

Ron Colarusso is professor, Department of Special Education, and coordinator of the Early Childhood/Special Education program at Georgia State University. Thomas Kana is a Ph.D. candidate, Georgia State University, and currently is working as project associate on Project SAMS, a model curricular process for persons with profound disabilities. 
Provisions include an individualized education program (IEP), due process, confidentiality, and placement in the least restrictive environment. If programs are not in place by the 1991-1992 school year, all federal funds for services to populations birth to age 6 as well as funding for related programs (e.g., research, personnel development, demonstration projects) will be lost to states not in compliance.

The state education agency working through local education agencies, or other contracted service agencies, is responsible for implementation of Part B. Federal funding is provided on a per-child basis according to those who are currently receiving services and to those who are identified as not presently receiving services but who will be served (each new school year). Appropriate service delivery models are left up to individual states. Services to the child may be direct or indirect. For example, a family may be recognized for its importance in development of the handicapped child and therefore may receive the only services considered

\section{Focus on Exceptional children}

ISSN 0015-511X FOCUS ON EXCEPTIONAL CHILDREN (USPS 203-360) is published monthly except June, July, and August as a service to teachers, special educators, curriculum specialists, administrators, and those concerned with the special education of exceptional children. This publication is annotated and indexed by the ERIC Clearinghouse on Handicapped and Gifted Children for publication in the monthly Current Index to Journals in Education (CIJE) and the quarterly index, Exceptional Children Education Resources (ECER). It is also available in microfilm from Xerox University Microfilms, Ann Arbor, MI. Subscription rates: Individual, $\$ 27$ per year; institutions, $\$ 36$ per year. Copyright (C 1991, Love Publishing Company. All rights reserved. Reproduction in whole or part without written permission is prohibited. Printed in the United States of America. Second class postage is paid at Denver, Colorado. POSTMASTER: Send address changes to:

$$
\begin{aligned}
& \text { Love Publishing Company } \\
& \text { Executive and Editorial Office } \\
& 1777 \text { South Bellaire Street } \\
& \text { Denver, Colorado } 80222 \\
& \text { Telephone (303) } 757-2579
\end{aligned}
$$

Edward L. Meyen

University of Kansas

Richard J. Whelan

University of Kansas Medical Center

Stanley F. Love Publisher
Glenn A. Vergason Georgia State University necessary for the good of the child while the child receives no direct service. Although services might be the more traditional school-based ones, the lead agency has the right to provide appropriate services through home-based models or by contracting with other government or private service providers such as day-care centers.

\section{PROVISIONS OF PART H}

Part $\mathrm{H}$ is a completely new section of the Education of the Handicapped Act. Congress declared, "There is an urgent and substantial need to enhance development, reduce potential future special education costs, maximize the potential for future independence, and to enhance a family's capacity to meet their infant/toddler's needs: [Title I, Part H, § 671 (a) $1,2,3,4]$. Financial assistance to states is provided to "develop and implement a statewide, comprehensive, coordinated, multidisciplinary, interagency program of early intervention services for handicapped infants and toddlers and their families" [Title I, Part H, \& 671 (b) 1]. The federal requirements are broad, giving individual states considerable autonomy as to who will be served, what state agencies will be charged with the responsibility to ensure services, and what type of delivery systems are appropriate.

\section{A COMPREHENSIVE SYSTEM FOR PART H}

A comprehensive statewide early intervention system must include the following 14 points in the infant and toddler program:

1. Definition of the term "developmentally delayed" by the state.

2. A timetable to endure services by the start of the fifth year. In years one and two, a lead agency shall be designated and the Interagency Coordinating council (ICC) must be named by the governor of each state. In years three and four, the state must adopt a public policy containing all components for statewide early intervention and demonstrate that it is in effect. Some latitude is allowed in the timeline as the law includes exceptions when "good faith effort" or "assurances" for appropriate programming are made.

3. A comprehensive, multidisciplinary evaluation for the infant/toddler and family.

4. An individualized family service plan (IFSP) developed for each infant/toddler and family by a multidisciplinary team including the parent Guardian; to be reviewed in at least 6 -month intervals. Each IFSP 
must include present levels of functioning, a statement of family strengths and needs, expected outcomes, specific services provided, projected dates of initiation and duration of services, name of the case manager, and steps taken to support the transition to the preschool program.

5. A comprehensive child find system and a system for referral.

6. A public awareness program with a focus on early identification.

7. A state central directory of services, resources, experts and demonstration projects.

8. A single line of responsibility in a designated lead agency for general administration, supervision, and monitoring of programs and activities and the promotion of interagency agreements.

9. A comprehensive system of personnel development.

10. A policy pertaining to contracting with service providers.

11. Procedures for timely reimbursement from agencies responsible for payment.

12. Procedural safeguards with respect to programs, infants/toddlers, and parents/guardians.

13. Standards to ensure appropriately trained, prepared, and qualified personnel.

14. A data collection system showing numbers served and types of services provided.

\section{Administrative Responsibilities}

Public Law 99-457 requires interagency cooperation and flexibility, especially for Part $\mathrm{H}$, as the provision calls for the "identification and coordination of all available resources within the state from federal, state, local, and private sources" [Title I, Part H, § 676 (b)9(B)]. State agencies must become adept at identifying such resources and working in concert rather than in adversarial positions. The goal of such cooperative activities should be improved unduplicated services and better use of limited financial resources. Private insurance is a largely untapped potential resource (Fox, Freedman, \& Klepper, 1989). Administration of Part $\mathrm{H}$ is the responsibility of each state's designated lead agency and interagency coordinating council (ICC).

\section{Lead Agency}

To participate in Part $\mathrm{H}$, each state must designate a lead agency responsible for developing the state's plan, coordinating the interagency services, and implementing the ser-

vices. Because of the variety of services needed from the health and social services areas, many states have chosen lead agencies other than education. The majority of states and territories (27) chose health, mental health, mental retardation, human services, or developmental disabilities lead agencies. Twenty-one states and territories chose their education agency. Three states-Maine, Rhode Island, and

TABLE 1

\section{Lead Agencies for Part $\mathrm{H}$ Services}

Agency

Department of

Education

Department of

Health

Department of Mental Health/
Mental Retardation/DD

Human Resources

Department of Public Welfare

Interagency Coordination Council

Source: Trohanis (1989)

\section{States/Territories}

Alabama, Colorado, Connecticut, Delaware Florida, Guam, Illinois, lowa, Louisiana, Maryland, Michigan, Minnesota, Missouri, Nebraska, New Hampshire, New Jersey, Oklahoma, Palau, South Dakota, Tennessee, Mariana Islands, Vermont

American Samoa, Alaska, Hawaii, Idaho, Kansas, Massachusetts, Mississippi, New Mexico, New York, Ohio, Puerto Rico, South Carolina, Utah, Virgin Islands, Washington, West Virginia, Wisconsin, Wyoming

Arizona, California, Indiana, Montana, Oregon, Virginia

Department of Human Services/ Arkansas, Washington, DC, Georgia, Kentucky, Nevada, North Carolina, North Dakota

Pennsylvania

Maine, Rhode Island, Texas 
Texas-designated the State ICC as the lead agency. Maryland chose its Office of Children and Youth. Table 1 identifies the lead agency for Part B in each state and territory.

\section{Interagency Coordination}

To ensure cooperation among the different agencies with the capacity to provide needed services, the law requires coordination of services at local, state, and federal levels. The lead agency is responsible for entering into formal interagency agreements as to each agency's responsibility for providing and paying for early intervention services. These formal agreements must be completed to qualify for fourth year funding.

A policy for contracting with public or private service providers also is required, along with procedures for achieving resolution of disputes about payments or other matters. Not only does this ensure services but also requires that the agencies each provide financial support when appropriate and maintain any services they provided before the law was enacted. The lead agency, however, is responsible for ensuring that services are provided, regardless of the agency involved. The components of Part $\mathrm{H}$ that have shown least progress across states are interagency agreements and those addressing financial responsibilities (Harbin, Gallagher, Lillie, \& Eckland, 1990).

An important provision in Part $\mathrm{H}$ is the "payor of last resort" [Title I, Part H, $§ 681$ (a,b)]. Identification and use of alternative public and private funds are needed to ensure success in financing services to infants/toddlers and their families. Various financing options may exist depending upon an individual's situation and the state's specifications. Families may be called upon to share the cost of services on a "schedule of sliding fees" that matches their ability to contribute at the appropriate level. Private insurance may be used to help defray costs. Medicaid also may be used for qualifying families. Agencies that have been providing needed services to eligible infants/toddlers must continue to do so, as Part $\mathrm{H}$ is not designed to supplant funding in such cases. Thus, a combination of sources might be needed. Interagency participation and cooperation are critically important in achieving the successful delivery of services to eligible infants/toddlers and their families.

Federal Interagency Coordination. In implementing the Handicapped Infants and Toddlers Program, Congress required that the Secretary of Education and the Secretary of Health and Human Services facilitate interagency coordination to ensure maximum funding of services from all agen- cies, and also ensure that funds are not being withdrawn or reduced in programs not directly under the Education of the Handicapped Act. Therefore, a Federal Interagency Coordinating Council (FICC) was established to coordinate Part $\mathrm{H}$ services at the federal level. In a joint study, the Department of Education and the Department of Health and Human Services (1989) identified 16 programs they administer that should contribute resources to the program:

- Handicapped Infants and Toddlers Program, Education of the Handicapped (Part $\mathrm{H}$ )

- Chapter 1 Handicapped Program, Education Consolidation and Improvement Act (Chapter 1)

- Services for Deaf-Blind Children and Youth, Education of the Handicapped (Part C)

- Assistance for Education of All Handicapped Children, Education of the Handicapped Act (Part B)

- Head Start Program, Head Start Act

- Medicaid, Social Security Act (Medicaid)

- Maternal and Child Health Block Grants, Social Security Act (MCH Block Grant)

- Child Welfare Services Program, Social Security Act (Child Welfare)

- Developmental Disabilities Basic State Grants Program, Developmental disabilities Assistance and Bill of Rights Act (ADD Basic State Grants)

- Alcohol, Drug Abuse and Mental Health Block Grant Program, Public Health Service Act (Mental Health Block Grant)

- Community Health Service Program, Public Health Service Act (Community Health)

- Indian Health Service Program, Indian Health Care Improvement Act (Indian Health)

- Migrant Health Services Program, Public Health Service Act (Migrant Health)

- Preventive Health and Health Services Block Grant, Public Health Service Act (Health Block Grant)

- Health Care for the Homeless Program, Homeless Assistance Act (Health for Homeless)

- Social Services Block Grant, Social Security Act (Social Services Block Grant).

These programs differ in eligible age groups and allow for discretion at the state level in prioritizing service emphases. Nevertheless, they all have the potential to use federal funds for the provision of services to handicapped infants and toddlers. Figure 1 presents the organizational location of each program. 


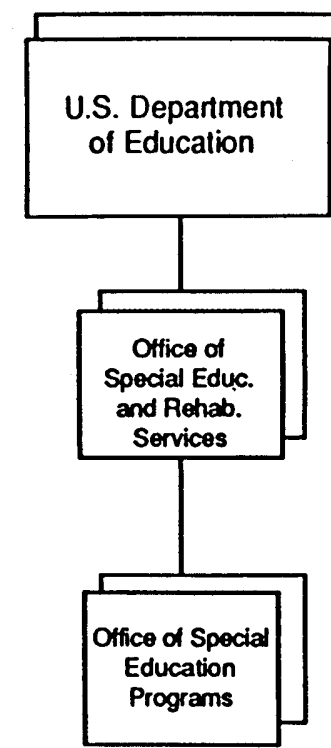

Handicapped Infants and Toddlers Program Deaf-Blind

Part B

Chapter 1--Handicapped

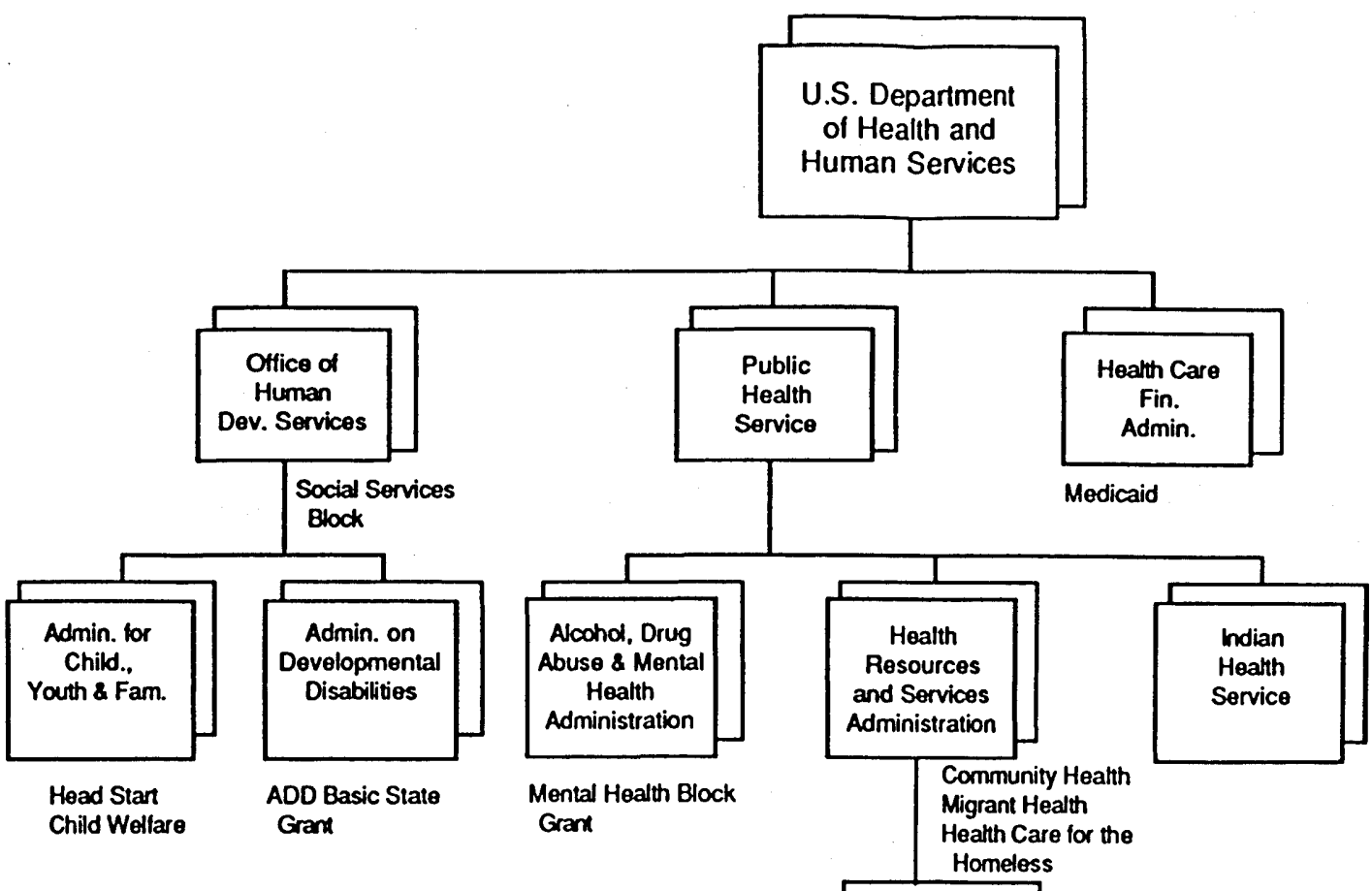

Bureau of

Maternal \&

Child Health \&

Resources

Development

MCH Block Grant

Source: Department of Education and Department of Health and Human Services, 1989.

\section{FIGURE 1 \\ Organizational Location of Programs \\ Providing at Least One Intervention Service}

State Interagency Coordination. A 15-member State Interagency Coordinating Council (ICC) is to be appointed by the governor to "advise and assist" the lead agency in performing its responsibilities. The ICC is responsible for:

1. Identifying various sources of fiscal and other support services.

2. Assigning financial responsibility to appropriate agencies.

3. Promoting interagency agreements and preparing federal application.

The ICC also is responsible for preparing and submitting an annual status report to the governor.

State ICC members must "reasonably" represent the population of the state and be composed of at least three par- ents, three public providers of early intervention services, one representative of the state legislature, one person involved in personnel preparation, and other representatives of appropriate agencies.

Some confusion exists in relation to the terms "advise" and "assist" as ICC responsibilities. Therefore, the range of authority of each state's ICC varies from a reactive/advisory role to a proactive policy-making authority (Harbin \& Van Horn, 1990).

The Executive Office of the Division for Early Childhood (DEC) of the Council for Exceptional Children (1991) has now recommended that the ICC be responsible for planning the entire system, including all ages, birth through 5 years. This is in response to the possibly "fragmented" system that may exist when two different agencies are responsible for 
Parts $\mathrm{H}$ and $\mathrm{B}$. If the ICC was entrusted with these additional responsibilities at this time, state education agencies currently planning and implementing Part B programs might experience significant changes in the manner in which they are conducting their overall systems.

Local Interagency Coordination. Because of the multidisciplinary approach required in the provision of services under Part $\mathrm{H}$, local interagency agreements are essential in providing comprehensive services. Assessment of the infant and family requires a multidisciplinary team. The intervention plan in most cases specifies services from various disciplines. Therefore, interagency coordination and formal agreements are essential because the direct services specified in the law are provided by different agencies and private service providers.

\section{Transition of Services}

The transition from Part $\mathrm{H}$ to Part B services creates a major problem in relation to the continuum of services, and requires interagency cooperation and planning especially if the Part $\mathrm{H}$ lead agency is not Education. Noneducation Part $\mathrm{H}$ lead agencies, which do not follow a traditional education model, provide services to the third birthday, whereas the traditional education model determines eligibility by age at the beginning of the school year and does not provide for new students during the school year based on age. Therefore, some children could go for close to a year without services.

To clarify the issue of continued services, the Office of Special Education Programs (Schrag, 1990, p. 1) has stated, "Under the statutory and regulatory provisions, children with handicapping conditions are eligible for a free appropriate public education upon their third birthday." This clearly places the responsibility under Part B at the child's third birthday regardless of when it occurs. If agreed, however, the child could continue to receive the same services from the same service providers for the remainder of the school year.

Another confounding variable in the transition between Part $\mathrm{H}$ and Part $\mathrm{B}$ is the eligibility definition. Two different definitions, especially when the Part B is more restrictive, could leave a Part $\mathrm{H}$-eligible child ineligible at the third birthday. The greatest concern occurs in states that have included "at-risk" in their definition of the developmentally delayed. A state education agency is allowed to adopt Part $\mathrm{H}$ eligibility criteria in determining eligibility for Part B except for the at-risk children who could not receive Part Bfunded services and be counted in the 3 to 5 year-old program (Tucker, 1990).
The service delivery model for the two programs may differ to the extent that services to the child or family could change radically. The individual family service plan (IFSP) of Part $\mathrm{H}$ might focus more specifically on services to the parents, such as parent training and counseling, which may not be included in an individualized education program (IEP) under Part B. Again, the state education agency may use IFSPs in place of IEPs under Part B, as long as they meet all the requirements specified for an IEP. Regardless, they may include parent counseling and training as a related service in the IEP (Tucker, 1990).

\section{Eligible Population}

Within Part $\mathrm{H}$ the term "handicapped infants/toddlers" includes ages birth through 2 years. As one of the 14 required components, states have been given individual responsibility in developing a definition for "developmental delay." Federal guidelines require that the identified population must be experiencing developmental delays as measured by appropriate diagnostic instruments and procedures in a minimum of one of five areas: cognitive development, physical development, language and speech development, psychosocial development, self-help skills. Also included are those whose diagnosed physical/mental condition has a "high probability" of resulting in developmental delays. At the state's discretion, those who would be "at risk" for developmental delays if services were not provided may also be included.

Determining the population to be served under Part $\mathrm{H}$ is challenging for a variety of reasons. One addresses the state of the art (science) in the ability to correctly identify handicapped infants and toddlers. It will be necessary to designate which type of handicapping conditions have to be present in order to be eligible for services. At such an early age, medical professionals can identify with some reliability medical conditions highly related to developmental delays. But reliable and valid assessment instruments that identify delays in developmental areas are not available. Infants/toddlers who do not exhibit medical syndromes will be a challenge because of the false positives and negatives associated with available assessment instruments. The developmental assessment of infants/toddlers requires teams of unavailable professionals highly skilled in both development and formal assessment.

Harbin, Terry, and Daguio (1989) note several difficulties in identification:

1. Detection, because of the complexity of developmental patterns.

2. The lack of predictive ability of assessment instruments. 
3. The lack of identification in the professional literature of what "risk factors" will be likely to result in disability or delay.

4. The possible existence of "contradictory policies from other federally mandated programs."

Harbin and Terry (1990) further note the lack in number of reliable and valid instruments for this age population, as well as the failure of traditional instruments to detect some delays/disabilities.

Including infants born with medical or environmental conditions that may be associated with handicapping conditions further complicates the issue. If an individual state decides to include the "at-risk" in developmental delay definition, that decision would impact both programming and funding. In addition to the "biologically at risk," Part $\mathrm{H}$ eligibility also may include the "environmentally at risk."

States are now struggling to decide if this "at-risk" population should be included in their definitions. If the environmentally at-risk are included, will special education be open to the same criticism received in the 1970s associated with mislabeling minorities, and will funding be available for a much larger population than originally projected? The transition issue discussed earlier also must be considered because "at-risk" is not a qualifying criteria for Part B. Therefore, services provided to children and their families might end abruptly on the child's third birthday.

This system of classification, left open to the discretion of each state, might best be described as "noncategorical" and definitely a departure from the traditional school-age handicapped definitions. Harbin et al. (1989) analyzed the draft definitions from 28 states and found large variations in the criteria for eligibility. States were similar in that most relied on traditional test instruments for determining eligibility. Developmental delay was determined by specified departures from the norm in either standard deviations or in percentage of delay. These ranged from $15 \%$ to $50 \%$ differences and 1 to 2 standard deviation differences, depending upon the individual state. Differences also existed in eligibility requirements in the number of areas in which delay must be present, one or two.

States "tended to ignore" problems presented by the inability to find valid instruments to measure developmental areas of these young children. When included, the "at-risk" definitions showed an even wider range of variation. For example, 36 different terms were used in the area of environmentally "at-risk." These terms sometimes were used singularly as a requirement for eligibility rather than as part of a more pro- fessionally valid multiple-risk scheme. The varied definitions will create problems when mobile American families lose eligibility by moving to states that have stricter criteria.

A population that will have a significant effect on Part $\mathrm{H}$ is composed of children who are exposed to cocaine (and other substances) in utero. This group is an example of the complexity involved in definitions and services. Depending on the professional source, the disabilities associated with substance abuse include poor feeding patterns, increased tremulousness and startles, increased muscle tone, and poor state control (Schneider, Griffith, \& Chasnoff, 1989). These infants will require immediate attention but will most likely qualify for Part $\mathrm{H}$ services if a state's eligibility criteria includes the biologically "at-risk."

Substance abuse population studies have involved mostly lower socioeconomic mothers. Therefore, many of these infants probably would meet eligibility criteria in states that include the "environmentally at-risk." Current professional literature, being primarily medical, addresses the young infant exclusively. Uncertainty exists as to the potential longterm outcome for those who have been interuturinally exposed to substances; however, there is speculation that the disabilities may exist into the school years and may require long-term treatment.

Only time and research can answer the questions of how long this population should be served and, if so, under what eligibility criteria services will be provided. Again, a substanceabused child may meet criteria for Part $\mathrm{H}$ services and be ineligible for Part B programs, presenting a transition problem.

Another issue related to the specified population is the service delivery model the myriad of exceptionalities requires. How will all children/families determined as eligible for services receive them? Once defined, diverse types of trained personnel will be required to dispense services. Families are to be included throughout the process; however, family assessment and intervention may become intrusive. Resistance by professionals to family wishes, which conceivably could become reality under these assessment and intervention requirements, goes against the spirit of the law. Although some questions raised are not exclusively targeted at operationalizing the definition, they do show that the definition will affect the other 13 required components.

\section{Service Delivery}

The intervention services specified as primary Part $\mathrm{H}$ services for infants/toddlers and their families are: family training and counseling, home visits, special instruction, speech 
pathology and audiology, occupational and physical therapy, psychological services, case management services (mandatory), diagnostic and evaluative medical services, early identification screening and assessment services, and health services necessary to enable the infant/toddler to benefit from the other early intervention services. These services are to be provided via qualified personnel. Many of these primary services are completely new to the traditional special education model; others are considered related services for older exceptional children.

Each state has autonomy in determining its own service delivery model(s). Although the lead agency is responsible for the assurance that all services are provided, it may not be responsible as the direct provider of services. Other public and private agencies may be the direct service provider to the child/family. The method and location of the service may vary depending on individual needs as determined by the multidisciplinary team and as specified on the IFSP.

In that the services provided to the infant/toddler and family may vary as a result of the diverse needs of this population, a continuum of service delivery models must be cost-effective as well as professionally sound. Because children and families are varied in their resources and needs, no one type of program is best. Appropriate IFSP plans will dictate the most effective interventions based upon child and family needs. Figure 2 presents a continuum of the main components needed for a comprehensive service delivery plan.

\section{Least Restrictive $\longrightarrow$ Most Restrictive \\ Direct Child Intervention \\ Mainstreamed class; $\rightarrow$ Segregated class; $\rightarrow$ Segregated center; supportive services mainstream center day/residential when appropriate \\ Family Intervention \\ Family Education $\rightarrow$ Family Counseling $\rightarrow$ Parent training for child intervention \\ FIGURE 2 \\ Services for Part $\mathrm{H}$ Intervention}

\section{Evaluation and Assessment}

From the time of referral, an evaluation of the referred child (including the family assessment) must be completed to allow enough time for the initial IFSP meeting to occur within 45 days. Reassessment must be done at least once a year but may occur more frequently when appropriate. The term "evaluation" means the procedures used to determine a child's initial continued eligibility. "Assessment" is an ongoing process to identify the eligible child's needs for program planning for the child and family. This assessment/evaluation must be both comprehensive and multidisciplinary. "Multidisciplinary" means that professionals from the appropriate disciplines who are trained to utilize appropriate methods and procedures must be included on the assessment/evaluation team. "Comprehensive" means that, as a minimum, the child's level of functioning must be determined in each of the following developmental areas:

- Cognitive development

- Physical development, including vision and hearing

- Language and speech development

- Psychosocial development

- Self-help skills.

Information related to the child's current health status and medical history also must be reviewed and included where appropriate. A family assessment (voluntary) must be designed to determine strengths and needs of the family related to enhancing the child's development.

\section{Individualized Family Service Plan (IFSP)}

As mentioned earlier, the initial IFSP meeting must occur within 45 days after the eligible child has been referred for evaluation. PL 99-457 is novel in its viewing of the family as critically important in its impact upon development (Trohanis, 1989). This is evident with the Part $\mathrm{H}$ intervention plan identified as an individualized family service plan. Each infant/toddler and family will have an IFSP developed by a multidisciplinary team including the parent/guardian. It is to be reviewed through a meeting or by other means in at least 6-month intervals, because of the rapid changes that occur in such young children. An annual meeting, however, must be conducted to evaluate the IFSP for the child and family. To remain useful and practical, these documents should allow for ease in changes coinciding with changes in child and family needs.

Each IFSP must include: present levels of functioning, a statement of family strengths and needs, expected outcomes, specific services provided, projected dates of initiation and duration of services, name of the case manager, and steps taken to support the transition to the preschool program. The IFSP includes both the required early intervention services and other services not required or covered under Part $\mathrm{H}$. 
Services not required under the law are included to provide a comprehensive picture of the child's total service needs (Tucker, 1990).

As children and families vary in their resources and needs, no one type of program is best. Appropriate IFSPs will allow for the most effective interventions based upon child and family needs. To maintain appropriate intervention services, these plans will allow for close monitoring of the child's developmental changes and the changes in family needs. Service delivery models probably will deviate from the traditional single setting and school-based models. Combinations of school- and home-based models, consultative models to parents, and the involvement of multiple agencies/programs will be incorporated to provide complete services (National Early Childhood Technical Assistance System, 1990). This might especially affect local education agencies in that they will be providing services under a relatively "novel" model(s).

Family input into the IFSP is a primary consideration. Traditionally, the school IEP process places the child receiving services at the forefront. Under Part $\mathrm{H}$, family members other than the child with a disability may be receiving services including assessment. It is indeed possible that family members other than the child identified as having the disability will receive services, sometimes exclusively, if such services are deemed critical to the development of the child with a disability.

Professionals and parents too often are at odds with each other. Values and priorities for goals and services often differ. The changing nature of today's family-cultural and economic issues, increased single and working parents-further complicates the relationship (Vincent \& Salisbury, 1988). Professionals and parents sometimes disagree over goals of intervention, methods used to achieve goals, priorities for treatment, or values related to treatment. Bailey (1987) has suggested the use of collaborative goal setting, along with the selection of intervention strategies, in attaining the specified goals. Parents then have a stake in the decision and may participate more actively in reaching goals. Also, if the child's needs are included and integrated into normal family activities and rituals, normalization is more likely to occur (National Early Childhood Technical Assistance System, 1990).

Dunst (1988) strongly advocates that parents become "empowered" to make decisions, advocate for themselves, and solve their own problems. This includes helping the family to access its own support, to avoid possible isolation as a unit (National Early Childhood Technical Assistance System,
1990). To be effective in collaborative goal setting, professionals must view families as "systems" and be able to assess family needs, interview effectively, negotiate joint solutions, and have the ability to match needs to available resources.

Gallagher, Harbin, Thomas, Clifford, and Wenger (1988) note the difficulties inherent in developing an all-encompassing policy covering the diverse needs of such a heterogeneous group of families. They suggest that the single common denominator among the group - the family having a child with a handicap or at-risk for a handicapping condition-"brings only a limited amount of communality to the group." Differences in variables, such as socioeconomic status, marital status, cultural background, geographic location, family values, attitudes, interests, desires, and coping strategies for dealing with this potentially stressful situation, leave policy makers the potential to design rules applicable and appropriate for some families and not others.

\section{Procedural Safeguards}

Procedural safeguards for Part $\mathrm{H}$ correspond to previously developed safeguards for PL 94-142. Although the safeguard regulations such as notification, native language, and timelines are straightforward, some safeguards are more controversial. For example, obtaining parental consent is required before conducting the initial evaluation and assessment, as well as providing services for the first time. Even though the parent has the right to refuse these services, override procedures are available to the Part $\mathrm{H}$ agency. A Part $\mathrm{H}$ agency may initiate a hearing under this part to override a parent's refusal of initial evaluation and assessment. If an impartial reviewer rules in favor of the Part $\mathrm{H}$ provider agency, the Part $\mathrm{H}$ provider agency may initiate the evaluation process without parental consent. The parent, however, may appeal this decision to a court of competent jurisdiction.

Part of the IFSP requires an assessment of the family's needs and resources as related to enhancing the development of their child with a disability. A statement of the family's strengths and needs is to be one of the components. This "virtually assures that the professionals involved will be collecting sensitive information about intrafamily relationships and special family problems" (Gallagher et al., 1988).

Family assessment holds the potential of becoming an intrusive process. Disclosure needed for appropriate assessment may be difficult to obtain. A family might gain an unwanted "label" in order to receive services. This may infringe upon a family's rights to confidentiality, mandated by procedural safeguards within the law. Gallagher et al. 
(1988) further note that the presence of multiple agencies (i.e., records passing between more hands and service agencies) will complicate this right to confidentiality even more.

Parents also have the right to "examine records related to assessment, screening, eligibility determination and the development of the IFSP" (Gallagher et al., 1988). Thus, records must be completed in a clear and understandable manner.

Coordination of services to Part $\mathrm{H}$-eligible children and families is necessary because of the variety of agencies and professionals involved in the delivery of services. A case manager must be assigned to each child and family to ensure coordination of the appropriate services. The case manager is to be assigned from the profession most immediately relevant to the infant's/toddler's or family's needs.

Although support for single responsibility for coordinating services is strong, case management as written in the law has received criticism. The term "case management" has been received negatively in that it implies the families are cases to be managed. The Division for Early Childhood (DEC) of the Council for Exceptional Children has recommended that the terms be changed to "service coordination" and "service coordinator." DEC recommends a broader basis for selection of the coordinator by eliminating the requirement that the coordinator come from the profession most immediately relevant to the needs, and allowing the parent to serve as co-service coordinator (Division for Early Childhood, 1990).

The concept of least restrictive environment (LRE) has to remain true to its "scientific" purposes (Smith \& Strain, 1988). In providing a continuum of services, the team must consider if, when, and how much integration would be of appropriate benefit to the infant/toddler and family. Services should be provided in the context of a family's community when it is deemed in the best interest of both the child and the family (National Early Childhood Technical Assistance System, 1990). Placement in a mainstreamed setting without trained personnel and planned integrative activities, however, is inappropriate. Once a system of programming has been put into place, continuing quality assurances and checks must remain in place.

\section{Personnel Preparation and Standards}

Another of the 14 requirements of Part $\mathrm{H}$ holds that a comprehensive system of personnel development be maintained. The law further dictates that appropriate personnel provide services that may include family training and counseling, home visits, special instruction, speech pathology and audiology, occupational and physical therapy, psycho- logical services, case management services (mandatory), diagnostic and evaluative medical services, early identification screening and assessment services, and health services necessary to enable the infant/toddler to benefit from the other early intervention services (not including general treatment or surgery).

These services are to be provided via qualified personnel including special educators, speech/language pathologists, occupational/physical therapists, psychologists, social workers, nurses, and nutritionists. Intervention will involve a multidisciplinary approach in which the interventionists work together as a team. The law requires that professionals have the highest entry-level academic degree needed for any state-approved or recognized certification, licensing, registration, or other comparable requirements that apply to that profession or discipline. This requirement has generated confusion focused on the meaning of "highest level of certification or licensing." It does not mean the standards of the profession or the highest level of standards. It means the highest entry-level standards for employment in a profession or discipline enacted by a state legislature or an authorized state agency. Also, the law does not designate specifically who should serve as case manager among specific groups of professionals. This raises questions as to what specific qualifications might be required of a case manager.

Bailey (1989) has specified certain issues for professionals working with young children with disabilities and unique to the requirements of Part $\mathrm{H}$ : the special professional competence and knowledge it takes to work with this age population, the possible varied contexts within which the child may be receiving services, multiagency involvement in service delivery and the various number and types of professionals who may be providing services. Also unique is the level of family involvement as both program contributors and receivers.

Once a system of programming has been put into place, continuing quality assurances and checks must remain present. One of the 14 points specifically calls for establishing and maintaining standards for personnel so they are appropriately and adequately trained. This includes establishing state-approved licenses, registration, or other approved requirements. Effective service providers are needed. Personnel shortages, certification standards, and the quality of training programs are all essential features to be addressed so that programming will remain effective (Burke, McLaughlin, \& Valdivieso, 1988).

The establishment of standards for this population is especially important due to the uniqueness of the client. Each 
discipline involved has it's own formal education track, it's own certification requirements, and it's own professional organizations. As Bailey (1989) notes, very little is done in the way of preparation for working with young children who are disabled (along with their families) in these separate professions. For example, an adequately licensed physical therapist may have little or no training or experience working with infants. Requirements must assure that personnel are adequately trained for this young population.

Compounding the potential difficulty in setting standards is the probable difficulty in filling positions. In a study reported by Meisels, Harbin, Modigliani, and Olson (1988), personnel shortages on a national level were recognized as a "serious policy issue" that all states will face in providing services. More than $68 \%$ of states reported a lack in necessary personnel preparation programs, more than $80 \%$ reported a lack of trained early intervention personnel, and almost $100 \%$ reported shortages in therapists.

Standards alone will not assure quality staff. Burke et al. (1988) reported on the shortage of availability of "welltrained personnel." Although training programs exist for persons who will work with infants and young children in all but seven states, existing programs are "unlikely" to be able to handle the immediate demands of PL 99-457. Faced with an increased demand, along with potential personnel shortages, states may be tempted to lower or alter standards for certification. Programs provided at institutions of higher learning and state certification standards must remain true to the intent of the law. Inservice training can provide necessary skills to professionals already in the field who may wish to work with this population, but the same threats to quality service exist here.

\section{SUMMARY/CONCLUSION}

The opportunity for change has been extended. Public Law $99-457$ is in place. The importance of families in the development of children has been acknowledged. The degree of cooperation needed between and among the various groups charged with implementation and provision of services has never been attempted to this extent. Professionals must remember whom the law is intended to serve and do their utmost to see that the services become reality.

\section{REFERENCES}

Bailey, D. B. (1987). Collaborative goal-setting with families: Resolving differences in values and priorities for services. Topics in Early Childhood Special Education, 7(2), 59-71.
Bailey, D. B. (1989). Issues and directions in preparing professionals to work with young handicapped children and their families. In J. J. Gallagher, P. L. Tronhanis, \& R. M. Clifford (Eds.), Policy Implementation and PL 99-457 (pp. 97-132). Baltimore: Paul H. Brookes.

Burke, P. J., McLaughlin, M. J., \& Valdivieso, C. H. (1988). Preparing professionals to educate handicapped infants and young children: Some policy considerations. Topics in Early Childhood Special Education, $8(1), 73-80$.

Department of Education and Department of Health and Human Services. (1989). Meeting the needs of infants and toddlers with handicaps: Federal resources, services, and coordination efforts in the Departments of Education and Health and Human Services. Washington, DC: U.S. Government Printing Office.

Division for Early Childhood, Council for Exceptional Children. (1990). Statement of the International Division for Early Childhood of the Council for Exceptional Children to the Congress of the United States with respect to reauthorization of Part $H$ and amendments to Part $B$ of the Education of the Handicapped Act regarding services to children from birth to age six years. Pittsburgh: Author.

Division for Early Childhood, Council for Exceptional Children. (1991). DEC recommendations for reauthorization of Part $H$ and amendments to Part $B$ of the Individuals with Disabilities Act. Pittsburgh: Author.

Dunst C. J. (1988). Resources, social support, and family functioning. In C. J. Dunst (Ed.), Enabling and empowering families. Cambridge, MA: Brookline Books.

Education of the Handicapped Amendments of 1986, PL 99-457, 1986.

Federal Register. (1989). Early intervention program for infants and toddlers with handicaps; Final regulations (Rep. No. 34 CFR Part 303). Washington DC: Department of Education.

Fox, H. B., Freedman, S. A., \& Klepper B. R. (1989). Financing programs for young children with handicaps. In J. J. Gallagher, P. L. Trohanis, \& R. M. Clifford (Eds.), Policy implementation and PL $99-457$ (pp. 169-182). Baltimore: Paul H. Brookes.

Gallagher, J. J., Harbin, G., Thomas, D., Clifford, R., \& Wenger, M. (1988). Major policy issues in implementing Part H, PL 99-457, infants and toddlers. Chapel Hill, NC: Carolina Institute for Child \& Family Policy.

Harbin, G. L., Gallagher, J. J., Lillie, T., \& Eckland, J. (1990). Executive summary: Status of states' progress in implementing Part $H$ of $P L$ 99-457 (Rep. No. 2). Chapel Hill, NC: Carolina Institute for Child \& Family Policy.

Harbin, G. L., \& Terry, D. (1990). Definition of developmentally delayed and at-risk infants and toddlers. Chapel Hill, NC: Carolina Policy Studies Program.

Harbin, G. L., Terry, D., \& Daguio, C. (1989). Status of the states' progress toward developing a definition for developmentally delayed as required by P.L. 99-457, Part H. Chapel Hill, NC: Carolina Policy Studies Program.

Harbin, G. L., \& Van Horn, J. (1990). Interagency coordinating council roles and responsibilities. Chapel Hill, NC: Carolina Policy Studies Program.

Meisels, S. J., Harbin, G., Modigliani, K., \& Olson, K. (1988). Formulating optimal state early childhood intervention policies. Exceptional Children, 55, 159-165.

National Early Childhood Technical Assistance System (1990). Least restrictive environment for infants, toddlers, and preschoolers. Chapel Hill, NC: Frank Porter Graham Child Development Center. 
Schneider, J. W., Griffith, D. R., \& Chasnoff, I.. J. (1989). Infants exposed to cocaine in utero: Implications for developmental assessment and intervention. Infants and Young Children, 2(1), 25-36.

Schrag, J. A. (1990). Age of eligibility for a free appropriate public education for preschool-aged children with handicaps under the Education of the Handicapped Act, as amended by P.L. 99-457. Washington, DC: United States Department of Education, Office of Rehabilitative Services.

Smith, J. S., \& Strain, P. S. (1988). Early childhood special education in the next decade: Implementing and expanding PL 99-457. Topics in Early Childhood Special Education, 8(1), 37-47.
Trohanis, P. L. (1989). An introduction to PL 99-457 and the national policy agenda for serving young children with special needs and their families. In J. J. Gallagher, P. L. Trohanis, \& R. M. Clifford (Eds.), Policy implementation and PL $99-457$ (pp. 1-18). Baltimore: Paul H. Brookes.

Tucker, J. A. (1990). Response to Pennsylvania questions on implementing a birth through five early intervention program. Washington DC: U.S. Department of Education, Office of Special Education \& Rehabilitive Services.

Vincent, L. J., \& Salisbury, C. L. (1988). Changing economic and social influences on family involvement. Topics in Early Childhood Special Education, 8(1), 48-59.

\section{PERMISSIONS AND COPYRIGHT}

All rights are reserved. No part of this publication may be reproduced, photocopied, faxed, stored in a retrieval system, or transmitted, in any form or by any means, electronic, mechanical, recording or otherwise, without the prior written permission of the publisher.
Back issues are available for sale. Reproduction requires permission and payment of fees. It is illegal and a violation of Federal copyright law to reproduce this publication without permission. Direct all inquiries to the permissions editor.

Errata for March, 1991 issue, last line of page 1 should read: been addressed in only one study.

\section{Professional update}

May 19-23, 1991

American Association on Mental Retardation Hyatt Regency Crystal City

Arlington, Virginia

Contact: AAMR, P.O. Box 1202, Washington, D.C. 20013

May 22-25, 1991

International Association of Special Education Conference

Milwaukee, Wisconsin

Contact: Dr. Barbara Reid or Dr. Todd Stephens (414) 472-3165
October 9-12, 1991

Council for Learning Disabilities

Marriott City Center

Minneapolis, Minnesota

Contact: CLD, P.O. Box 40303, Overland Park, Kansas 66204

\section{October 9-12, 1991}

Division on Career Development of CEC

Holiday Inn Crowne Plaza Hotel

Kansas City, Missouri

Contact: CEC

1920 Association Drive

Reston, Virginia 22091 